\title{
Comprehensive two-dimensional separation for the analysis of alkylphenol ethoxylates employing hydrophilic interaction chromatography coupled with ion mobility-mass spectrometry
}

\author{
Qiang Ma ${ }^{\mathrm{a}, \mathrm{b}, *}$, Guang-Cheng Xi ${ }^{\mathrm{b}}$, Chao Wang ${ }^{\mathrm{b}}$, Hua Bai ${ }^{\mathrm{b}}$, Qing Zhang ${ }^{\mathrm{b}}$, Hai-Wei Xi ${ }^{\mathrm{b}}$, \\ Zi-Ming Wang ${ }^{\mathrm{c}}$, Liang-Hong Guo ${ }^{\mathrm{a}, *}$ \\ a State Key Laboratory of Environmental Chemistry and Ecotoxicology, Research Center for Eco-Environmental Sciences, Chinese Academy of Sciences, Beijing 100085, China \\ ${ }^{\mathrm{b}}$ Chinese Academy of Inspection and Quarantine, Beijing 100123, China \\ c College of Chemistry, Jilin University, Changchun 130012, China
}

\section{A R T I C L E I N F O}

\section{Article history:}

Received 10 November 2011

Received in revised form 7 February 2012

Accepted 16 February 2012

Available online 25 February 2012

\section{Keywords:}

Alkylphenol ethoxylates

Hydrophilic interaction chromatography

Ion mobility-mass spectrometry

Two-dimensional separation

\begin{abstract}
A B S T R A C T
A comprehensive two-dimensional system coupling hydrophilic interaction chromatography (HILIC) and ion mobility-mass spectrometry (IM-MS) has been developed for the separation and analysis of alkylphenol ethoxylates (APEOs). The first-dimensional HILIC was performed on porous silica stationary phase using acetonitrile-water gradient elution, which was readily compatible with electrospray ionization (ESI), and enabled good chromatographic separation of APEO oligomers on account of their differences in ethoxy chain length. Maintaining the fidelity of pre-ionization resolution in the first dimension, the second-dimensional IM-MS employed a hybrid quadrupole ion mobility time-of-flight mass spectrometer and added an orthogonal post-ionization separation for APEOs based on their size, shape and electric charge during a very short period of $13.0 \mathrm{~ms}$. By virtue of the combination of HILIC and IM-MS, comprehensive resolution according to both hydrophobicity difference and mobility disparity has been achieved for APEO ethoxy homologues. The orthogonality of the developed two-dimensional system was evaluated with the correlation coefficient and peak spreading angle of 0.2191 and $77.34^{\circ}$ for octylphenol ethoxylates (OPEOs), and 0.1490 and $81.43^{\circ}$ for nonylphenol ethoxylates (NPEOs). A significant enhancement in peak capacity was achieved for the comprehensive two-dimensional plane with the actual peak capacity calculated to be approximately 7 and 122 times higher than that of the two dimensions used alone, respectively. The attractive potential for removing the effects of isobaric interference of APEOs by the rapid and solvent-free ion mobility approach was also highlighted.
\end{abstract}

(C) 2012 Elsevier B.V. All rights reserved.

\section{Introduction}

Alkylphenol ethoxylates (APEOs) make up one of the largest classes of surfactants, produced by reacting alkylphenols (APs) with ethylene or propylene oxide, and have been widely used as detergents, emulsifiers, solubilizers, wetting and dispersing agents in industrial, agricultural and household applications [1,2]. Among APEOs, octylphenol ethoxylates (OPEOs) and nonylphenol ethoxylates (NPEOs) are two of the most common non-ionic surfactants in the marketplace. As a result of the extensive usage, APEOs are incorporated into the environment by various ways, primarily through industrial and municipal wastewater discharges, manufacture of

\footnotetext{
* Corresponding authors at: State Key Laboratory of Environmental Chemistry and Ecotoxicology, Research Center for Eco-Environmental Sciences, Chinese Academy of Sciences, Beijing 100085, China. Tel.: +86 10 62849685; fax: +86 1062849685.

E-mail addresses: maqiang1129@yahoo.com.cn(Q. Ma), LHGuo@rcees.ac.cn (L.-H. Guo).
}

APEOs-containing products, etc. [3,4]. The broad environmental presence of APEOs (ambient air, surface water, wastewater, soil, sediments, biota, etc.) [5-7], is solely a consequence of anthropogenic activity. Biodegradation of APEOs can subsequently occur based on a mechanism of stepwise loss of ethoxy groups under both aerobic and anaerobic conditions, resulting in the formation of more toxic and more persistent metabolites than the parent compounds: short-chain alkylphenol mono- and diethoxylate $\left(\mathrm{AP}_{1} \mathrm{EO}\right.$ and $\mathrm{AP}_{2} \mathrm{EO}$ ), alkylphenoxy carboxylates (APECs), carboxyalkylphenol ethoxycarboxylates (CAPECs) and fully de-ethoxylated APs [8-10]. The main environmental concern about APEOs is usually not the toxicity of these compounds themselves, but rather the endocrine disruption potential of their decomposition products, which are suggested to mimic the natural hormones by interacting with the estrogen receptor [11-14]. The widespread use of APEOs, together with their estrogenic properties, has initiated an incitement for regulatory actions [15-19].

Great public concern about the effects of APEOs and their metabolites on wildlife and human health, and about their 


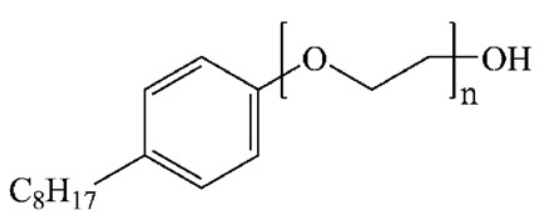

\section{Octylphenol ethoxylates (OPEOs)}

\section{Nonylphenol ethoxylates (NPEOs)}

Scheme 1. Chemical structures of OPEOs and NPEOs.

environmental fate, has led to the development of various analytical methods for the determination of these substances. APEOs are mixtures of homologues with different alkyl groups and oligomers with different numbers of ethylene oxide units. The considerable analytical challenge lies in the chemical complexity of APEOs, making the separation and characterization difficult. Given that their properties, toxicities, environmental occurrence and fate may depend on structural details, information about the exact oligomer distribution of APEOs is essential in assessing the associated environmental impact and risks. A sophisticated and specific method is therefore needed for their analysis.

Traditional methodologies of analysis are based on gas chromatography (GC) coupled with flame ionization detection (FID) [20], electron capture detection (ECD) [21] and low-resolution mass spectrometry (LRMS) [22,23] operating in electron ionization (EI) or chemical ionization (CI) mode. Nevertheless, the GC-based approaches are only appropriate for APEOs with a low number of ethylene oxide groups. Their applicability has been confined to short-chain ethoxylates due to volatilization issues. Further time-consuming derivatization procedures must be included to improve their volatility, which may possibly lead to potential analytical errors due to differences in reaction kinetics for individual oligomers and the formation of by-products during in-sample treatment. Alternatively, liquid chromatography (LC) hyphenated with ultraviolet detection $[24,25]$ or fluorescence detection $[26,27]$ has been applied for the routine analysis of APEOs. However, these optical detectors are becoming out of date when faced with MS detection, due mainly to the lack of specificity in analysis. In the past few years, growing attention has been paid to LC-MS methodologies for the identification and quantification of APEOs. Atmospheric pressure ionization (API) or matrix-assisted laser desorption ionization (MALDI) [28] sources, combined with various mass analyzers (single quadrupole [29], triple quadrupole [30,31], ion trap [32], and quadrupole/time-of-flight [33]) offer a broad range of instruments for use. Analytical advantages of superior sensitivity and specificity make LC-MS a better choice than titrimetric, colorimetric and spectroscopic detection.

A two-dimensional separation is generally considered to be advantageous over its one-dimensional counterpart for resolving complex mixtures because of extended peak capacity and higher resolution. It is recommended that the two dimensions be connected in an on-line manner, referred to as a comprehensive two-dimensional separation, rather than in an off-line or heart-cut manner, in order to approach the ideal multiplicative total of peak capacity. To date, a wide variety of separation techniques have been mutually interfaced to construct comprehensive two-dimensional separation systems [34-37]. Currently, LC in conjunction with ion mobility-mass spectrometry (IM-MS) is becoming increasingly popular for complex mixture analysis, due to complementary separation steps and elevated peak capacity. The applications include the analysis for environmental pollutants
[38], rat urinary metabonome [39], human plasma proteome [40], peptide mixtures [41], pharmaceutical formulation [42], etc. The principle for IM-MS has been described in detail elsewhere [43] Briefly, IM-MS is a gas phase electrophoretic technique that allows ionized target molecules to be separated on the basis of their mobility in the presence of an inert carrier gas and under the influence of a weak electric field. The system incorporating ion mobility separation in tandem with LC and MS enables the initial separation of components by LC, then transfers and disperses the ions generated in the ion source according to their differing mobility, and finally records their mass-to-charge ratio $(\mathrm{m} / \mathrm{z})$ by a time-offlight (TOF) mass analyzer. In the current study, the separability afforded by different liquid chromatographic modes and ion mobility technique was explored to address the challenge derived from the compositional complexity of APEOs. Based on the experimental investigation, a comprehensive two-dimensional system hyphenating hydrophilic interaction chromatography (HILIC) and IM-MS (HILIC $\times$ IM-MS) was developed for the separation and analysis of APEOs.

\section{Experimental}

\subsection{Materials}

Technical oligometric standards of $\mathrm{OP}_{10} \mathrm{EO}$ (a mixture of OPEOs with an average of 10 ethylene oxide units) and $\mathrm{NP}_{10} \mathrm{EO}$ (a mixture of NPEOs with an average of 10 ethylene oxide units) were purchased from Tokyo Chemical Industry (Tokyo, Japan). Chemical structures of OPEOs and NPEOs are shown in Scheme 1. Sodium formate and leucine enkephalin were obtained from Sigma-Aldrich (St. Louis, MO, USA). Acetonitrile of LC-MS grade (J.T. Baker, Pittsburgh, PA, USA) and Milli-Q ultrapure water (Millipore, Bedford, MA, USA) were used as mobile phase constituents for HILIC separation.

\subsection{Instrumentation}

The HILIC separation of APEOs was performed on an ACQUITY LC system (Waters, Milford, MA, USA) equipped with a binary solvent manager, a sample manager and a column heater. A Waters Atlantis HILIC Silica analytical column $(150 \mathrm{~mm} \times 2.1 \mathrm{~mm}, 3 \mu \mathrm{m})$, packed with underivatized porous silica stationary phase was utilized. The chromatographic elution was conducted with binary mobile phase gradient consisting of an organic part - acetonitrile (A) and an aqueous part - water (B) at a flow rate of $0.25 \mathrm{~mL} / \mathrm{min}$. Initial gradient condition was set to $0 \% \mathrm{~B}$ before embracing a linear gradient increase to $35 \%$ B over $10 \mathrm{~min}$ and then held for $1 \mathrm{~min}$. At $13 \mathrm{~min}$, the gradient was programmed to the initial conditions. The column temperature was maintained constantly at $30^{\circ} \mathrm{C}$. The samples were kept at $10^{\circ} \mathrm{C}$ in the thermostated sample manager compartment and a sampling volume of $10 \mu \mathrm{L}$ was injected for each run 
The strong and weak needle wash solvents were $200 \mu \mathrm{L}$ of $100 \% \mathrm{~B}$ and $600 \mu \mathrm{L}$ of $100 \% \mathrm{~A}$, respectively.

The entire column eluent from HILIC was directed into a SYNAPT HDMS hybrid quadrupole ion mobility orthogonal acceleration time-of-flight mass spectrometer (Waters, Manchester, UK). An electrospray ionization (ESI) interface operating in positive mode enabled ionization of APEOs with a capillary voltage of $3.5 \mathrm{kV}$ and a nitrogen desolvation gas flow rate of $300 \mathrm{~L} / \mathrm{h}$ at a temperature of $350^{\circ} \mathrm{C}$. A sampling cone voltage of $35 \mathrm{~V}$ and an extraction cone voltage of $4.0 \mathrm{~V}$ were set for the experiment. The quadrupole mass filter was run in the wide-band pass-through mode. The APEO ions were then accumulated into a trap ion guide region at the pressure of 0.03 mbar with argon trap collision energy set at $6.0 \mathrm{~V}$ and nitrogen trap gas flow rate of $1.5 \mathrm{~mL} / \mathrm{min}$. The ions were subsequently pulsed into an ion mobility drift cell over a period of $100 \mu \mathrm{s}$ to undertake an ion mobility-based separation at $0.55 \mathrm{mbar}$. Each individual mobility experiment was $13.0 \mathrm{~ms}$ long with a $300 \mathrm{~m} / \mathrm{s}$ traveling wave amplitude ramping from 5.0 to $12.0 \mathrm{~V}$ and a nitrogen mobility gas flow rate of $24 \mathrm{~mL} / \mathrm{min}$. The ions passing through the drift cell were then continually released to a transfer ion guide region with argon transfer collision energy set at $4.0 \mathrm{~V}$. Finally, the mobility-separated ions were conveyed to the reflection TOF mass analyzer operating in V-Optics mode whilst maintaining the temporal separation. Data were recorded over the range of $\mathrm{m} / \mathrm{z}$ $100-1500 \mathrm{Da}$, with the repeated 1.0 -s scan time and a 0.02 -s interscan interval. The TOF mass analyzer was externally calibrated with a sodium formate solution. All analyses were acquired using an independent LockSpray reference sprayer infusing $200 \mathrm{ng} / \mathrm{mL}$ protonated leucine enkephalin $(\mathrm{m} / \mathrm{z} 556.2771 \mathrm{Da})$ at a flow rate of $5 \mu \mathrm{L} / \mathrm{min}$ to verify mass accuracy. Instrumentation control, data acquisition, and mining were carried out by MassLynx version 4.1 and DriftScope version 2.0 software supplied with the instrument (Waters, Manchester, UK).

\section{Results and discussion}

\subsection{Selection of ionization mode for the analysis of APEOS}

ESI and atmospheric pressure chemical ionization (APCI) are the commonly used ionization sources in LC-MS. Both of them have been applied to APEOs detection. ESI is the most frequently used ionization technique and is ideally suited for the analysis of APEO surfactants. As previously reported by several authors [44-46], the high surface activity of APEOs, plus their strong affinity towards alkali-metal and other cations, leads to efficient formation of different adduct ions during the electrospray process with better resulting sensitivity than $\mathrm{APCI}$. In our work, both ESI and $\mathrm{APCI}$, operating in either positive or negative ionization mode, have been investigated. Initial studies to compare the performance of ESI and APCI for the analysis of APEOs were conducted by infusing the reference standard solutions into the spectrometer employing an integrated syringe pump. Relevant instrumental settings, such as source and desolvation temperatures, capillary voltage, sampling and extraction cone voltages, etc. for ESI, and source and probe temperature, corona voltage, sampling and extraction cone voltages, etc. for APCI, were optimized. The studied APEOs gave characteristic signals in positive but not in negative mode. A much higher level of response was provided with ESI, approximately 6 times higher than that of APCI. Considering the better sensitivity obtained, positive ESI was selected as the ionization mode in the present study.

\subsection{Liquid chromatographic separation of APEOs}

The compositional complexity of APEOs, as mixtures of ethoxy homologues and alkyl isomers, is the main drawback to acquiring a good chromatographic separation. The appropriate chromatographic modes were firstly investigated based on four different liquid chromatographic mechanisms, i.e., reversed-phase liquid chromatography (RPLC), normal-phase liquid chromatography (NPLC), HILIC as well as a mixed-mode liquid chromatography. A quick and convenient comparative evaluation on the separation efficiency for APEOs was carried out by coupling LC with a photodiode array detector. The column effluent in each individual chromatography was subjected to ultraviolet detection at the wavelength of $225 \mathrm{~nm}$, the maximum absorbance wavelength of APEOs, for optimum sensitivity. Enough volumes of mobile phase equilibration and constant column temperatures were ensured to achieve reproducible and stable column performance. The optimum analytical conditions in every chromatographic system are shown in Supplementary Material, Table S1. Information on chromatographic column, stationary phase type, column temperature, mobile phase composition, gradient elution program, flow rate and detection wavelength are included.

RPLC is the most universally implemented chromatographic technique in LC-MS. In this study, a Kromasil $C_{18}$ $(250 \mathrm{~mm} \times 4.6 \mathrm{~mm}, 5 \mu \mathrm{m})$ column allowed for resolution of APEOs according to the character of their hydrophobic alkyl chain moiety. As displayed in Fig. S1a and S1b (see Supplementary Material), the main peak emerging in the chromatograms represented the coeluting whole range of ethoxylate oligomers with the given alkyl (octyl or nonyl) chain length. Although this coelution has been claimed to be an advantage in increasing detection sensitivity, quantification for individual ethoxymers is severely compromised due to the substantially differing response factors with the increasing degree of ethoxylation [47]. The coelution also brings about competitive ionization during electrospray process. And the isobaric interference between doubly charged adduct ions of highly ethoxylated APEOs and singly charged adduct ions of less ethoxylated APEOs can occur. Given the disadvantages from the coelution of ethoxylate homologues in RPLC, NPLC with a ZORBAX $\mathrm{NH}_{2}$ aminopropyl-bonded stationary phase has been attempted for the separation of APEOs. As shown in Fig. S1c and S1d (see Supplementary Material), efficient chromatographic separation of OPEOs and NPEOs in line with increasing ethoxylate number was achieved with average resolutions of 5.40 and 3.15, respectively. Despite excellent resolving capability, the non-polar mobile phase solvents involved in NPLC are not directly compatible with ESI, which exhibits sensitive signals for APEOs. Though there is an alternative to apply a post-column split to the eluent and add a make-up flow containing polar aqueous buffer modifier contributing to ionization of the analytes of interest, impaired sensitivity was observed. A mixed-mode liquid chromatographic system employing an MSpak GF-310 2D highly cross-linked polyvinyl alcohol gel column and an acetonitrile-water reversed-phase mobile phase was tested next. It was reported that the separation of APEOs on this column basically relied on size exclusion mechanism associated with slight effects of partition and adsorption $[48,49]$. The experimental result demonstrated that adjacent OPEO or NPEO oligomers were closely eluted and not well resolved from each other (Fig. S1e and S1f, see Supplementary Material). The average resolutions obtained were 0.51 and 0.33 for OPEOs and NPEOs, respectively, far from baseline separation. It should be noted that higher ethoxylated and larger homologues were eluted first, whereas lower ethoxylated and smaller homologues towards the end, exhibiting a reverse elution order to NPLC.

HILIC was performed on an Atlantis HILIC Silica stationary phase $(250 \mathrm{~mm} \times 4.6 \mathrm{~mm}, 5 \mu \mathrm{m})$. The retention of APEOs in HILIC mainly depends on their competition with mobile phase for the adsorption on the residual silanol sites of porous silica stationary phase surface. Since the organic portion of mobile phase is weak solvent and the aqueous portion is strong solvent, APEOs are relatively retained 

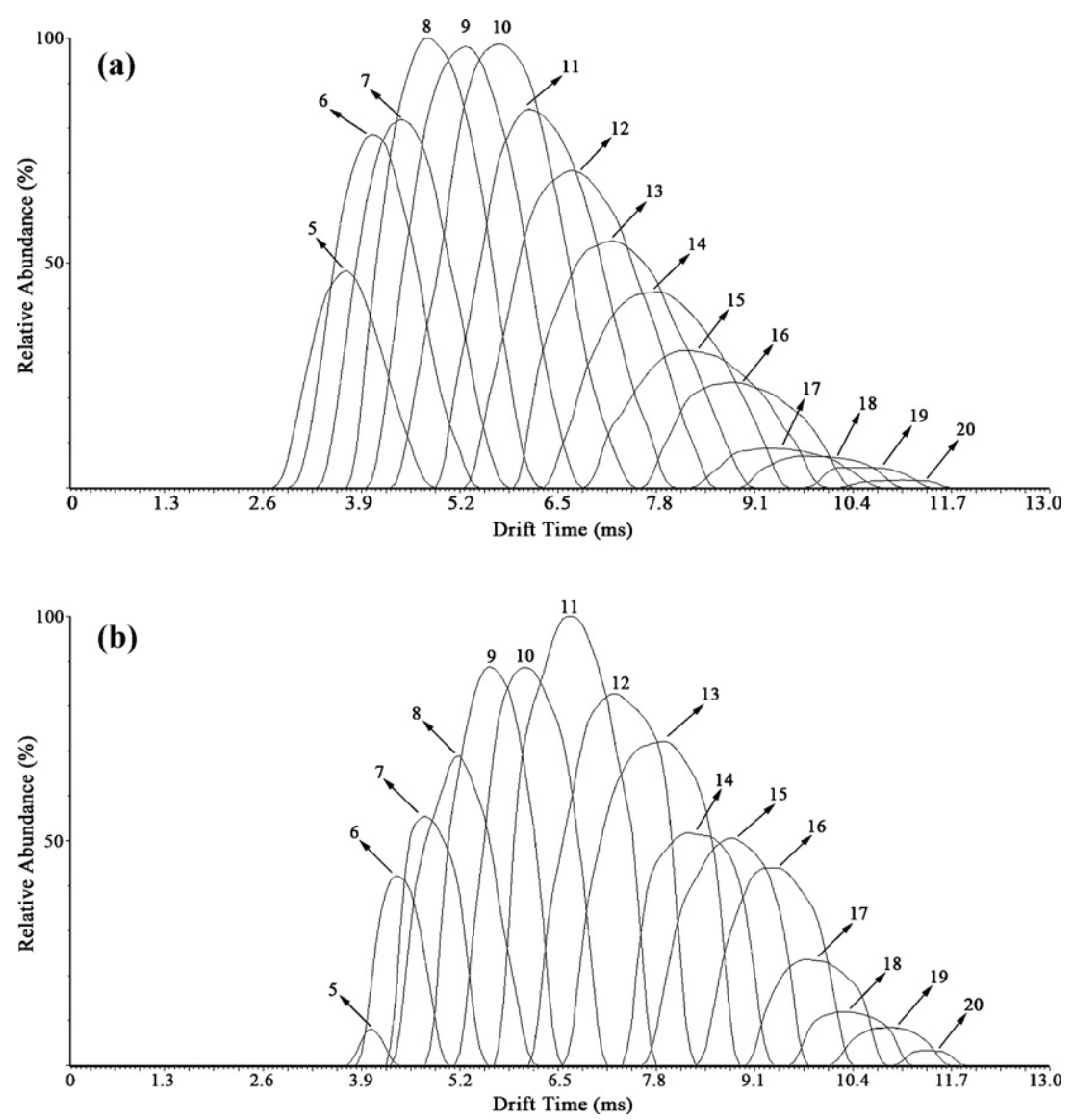

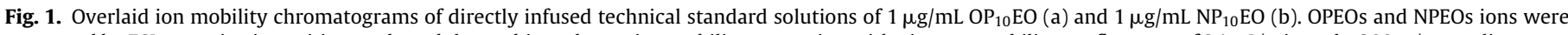

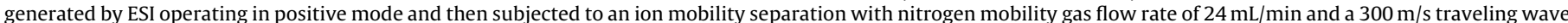

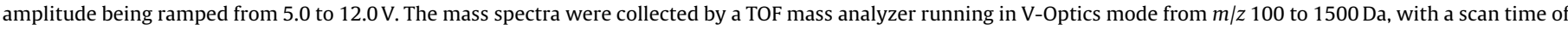

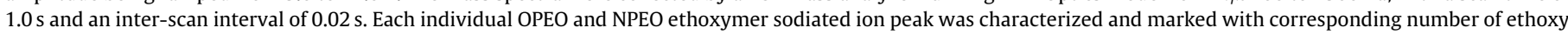
groups.

with organic rather than aqueous mobile phase. From our observation, the type of organic modifier had a major impact on the separation of APEOs. Three water-miscible organic solvents commonly used in LC, i.e., acetonitrile, methanol and tetrahydrofuran, were separately paired with water as the mobile phase for assessing their chromatographic behaviors. The result demonstrated that acetonitrile gave the most symmetrical peak shape and best resolution for APEOs. This is probably attributable to its aprotic nature to encourage hydrogen bonding between the analytes and the residual silanols on the surface of stationary phase, thus increasing retention. HILIC also favors acetonitrile as the organic part of mobile phase in terms of lower viscosity, which is beneficial to alleviating column backpressure. Meanwhile, the volatile acetonitrile-rich mobile phase provides favorable conditions for efficient droplet formation and desolvation within ESI source, resulting in enhanced mass spectrometric sensitivity. The target APEO compounds have a wide range of octanol/water partition coefficients, calculated by an open source Estimation Program Interface (EPI) Suite version 4.0 software. The logarithmic value $\left(\log K_{\text {ow }}\right.$ ) ranges from -0.13 to 3.99 for OPEOs and from 0.36 to 4.48 for NPEOs, suggesting considerable disparity in hydrophobicity from more lipophilic short-chain to more hydrophilic long-chain APEO ethoxymers. To acquire optimal band spacing for multicomponent APEO ethoxymers during a reasonable period of time, a gradient elution program was applied. The mobile phase gradient for optimum chromatographic performance was chosen through extensive tests on initial solvent strength, gradient segments and flow rate to mediate the retardation of individual APEO homologues. The elution program was optimized to start with $0 \%$ B proceeding to $35 \%$ B over 30 min and then return back to the initial conditions at $35 \mathrm{~min}$. As indicated in Fig. S1g and S1h (see Supplementary Material), individual ethoxylate oligomers were completely separated from each other, with average resolutions of 1.71 and 1.60 for OPEOs and NPEOs, respectively. In the case of OPEOs, $\mathrm{OP}_{5} \mathrm{EO}$ ethoxymer with the shortest ethoxylate chain and highest hydrophobicity was eluted earliest in the chromatogram with a retention factor $k^{\prime}$ of 0.80 , while $\mathrm{OP}_{20} \mathrm{EO}$ ethoxymer with the longest ethoxylate chain and lowest hydrophobicity was eluted last with a retention factor $k^{\prime}$ of 2.78. As for NPEOs, $\mathrm{NP}_{5}$ EO ethoxymer was eluted first with a retention factor $k^{\prime}$ of 0.77 , while $\mathrm{NP}_{20}$ EO ethoxymer was eluted towards the end with a retention factor $k^{\prime}$ of 2.74 , in the order of decreasing hydrophilicity. On the whole, HILIC driven by an acetonitrile-rich and low aqueous mobile phase at a flow rate of $1.0 \mathrm{~mL} / \mathrm{min}$ on an Atlantis HILIC Silica chromatographic column $(250 \mathrm{~mm} \times 4.6 \mathrm{~mm}, 5 \mu \mathrm{m})$ at a temperature of $30^{\circ} \mathrm{C}$, gave satisfactory resolution for APEOs, and was configured as the chromatographic mode of the first dimension.

\subsection{Ion mobility separation of APEOs}

Preliminary experiments aiming at optimizing ion mobility separation conditions were carried out by individually infusing the technical oligometric standard solutions of $\mathrm{OP}_{10} \mathrm{EO}$ and $\mathrm{NP}_{10} \mathrm{EO}$ into the ESI interface of the spectrometer by use of an integrated syringe pump. Three parameters, i.e., IM-MS gas flow rate, traveling wave velocity and traveling wave height, which are directly related to the effects on ion mobility separation, were tuned to optimize 

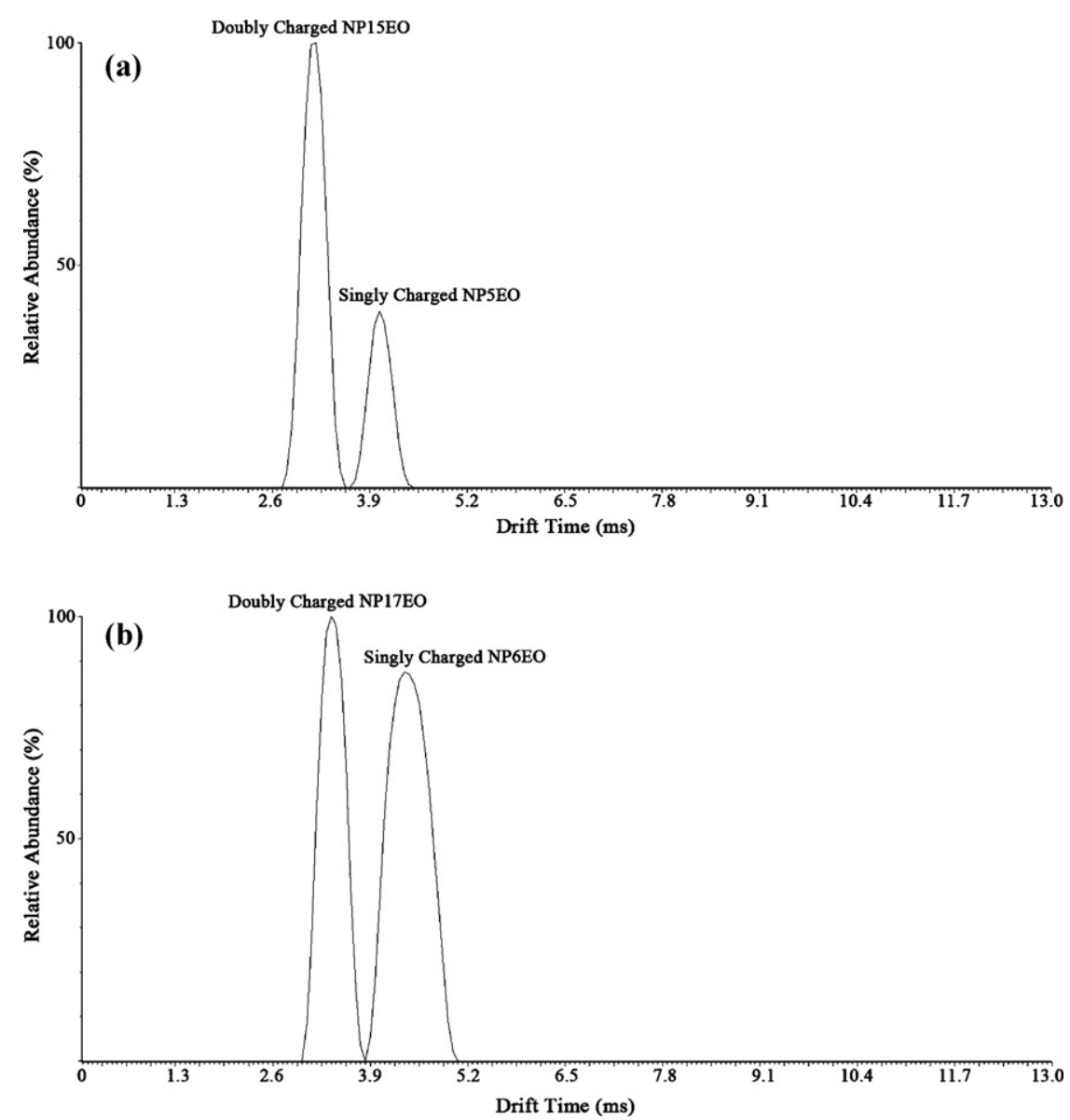

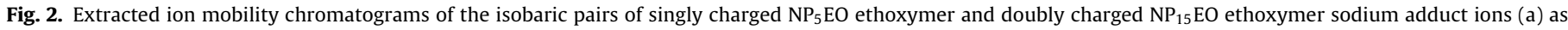
well as singly charged $\mathrm{NP}_{6}$ EO ethoxymer and doubly charged $\mathrm{NP}_{17}$ EO ethoxymer sodium adduct ions (b).

the mobility separation. Successively leaving two of the three variables fixed, the third was adjusted until the optimal ion mobility separation was obtained under the circumstance. The parameter of IM-MS gas flow rate was sample-dependent and found to show great impact on ion mobility separation of APEOs. By varying the IM-MS gas flow rate from 5 to $40 \mathrm{~mL} / \mathrm{min}$, a flow rate of $24 \mathrm{~mL} / \mathrm{min}$ appropriately allowed all analyte ions to move across the ion mobility drift tube during one pulse cycle. It was observed that increased traveling wave velocity would widen the drift time distribution profile, while increased traveling wave height would narrow it. A $300 \mathrm{~m} / \mathrm{s}$ traveling wave ramping from 5.0 to $12.0 \mathrm{~V}$ gave optimum ion mobility separation in the experiment. The reconstructed ion mobility chromatograms for OPEOs and NPEOs are shown in Fig. 1.

The APEO ions passed through the ion mobility gas with drift time being dependent on their mobility values. In this case, APEO ethoxymers were broadly fractionated along their ethoxy oxide unit length. The rapid ion mobility separation occurred during a very short period of $13.0 \mathrm{~ms}$ with the mean peak width at half height of $1.79 \mathrm{~ms}$ for OPEOs and $1.38 \mathrm{~ms}$ for NPEOs. An average $0.48-\mathrm{ms}$ difference in ion mobility drift time was observed for adjacent OPEO peaks from octylphenol pentaethoxylate $\left(\mathrm{OP}_{5} \mathrm{EO}\right)$ ethoxymer to octylphenol eicosaethoxylate $\left(\mathrm{OP}_{20} \mathrm{EO}\right)$ ethoxymer. $\mathrm{OP}_{5} \mathrm{EO}$ drifted fastest, while $\mathrm{OP}_{20} \mathrm{EO}$ was the last analyte to travel through the pressurized mobility cell. The mean resolution for OPEOs was computed to be 0.17 . The average drift time difference and resolution achieved for adjacent NPEO peaks from nonylphenol pentaethoxylate $\left(\mathrm{NP}_{5} \mathrm{EO}\right)$ ethoxymer to nonylphenol eicosaethoxylate $\left(\mathrm{NP}_{20} \mathrm{EO}\right)$ ethoxymer were $0.50 \mathrm{~ms}$ and 0.21 , respectively. Despite relatively limited resolving power and less variables to be optimized in comparison with HILIC, the timescale of ion mobility separation $(13.0 \mathrm{~ms})$ fits seamlessly between that of HILIC elution time (10 min) and fast-scanning TOF-MS acquisition time (65 $\mu \mathrm{s} / \mathrm{scan})$. The ion mobility separation can therefore occur within one HILIC chromatographic peak (the mean peak width at half height of $4.47 \mathrm{~s}$ for OPEOs and $7.09 \mathrm{~s}$ for NPEOs) while effectively feed components into TOF-MS very rapidly. In addition, as a post-ionization gas phase separation method, ion mobility separation occurs in milliseconds resulting in very high peak production rates.

As a result of multiple charging phenomenon associated with ESI, some APEO oligomers may possibly carry both single and double charges simultaneously during the electrospray procedure, which may impair accurate quantitation for singly charged low ethoxylated APEOs owing to the presence of doubly charged highly ethoxylated APEOs with identical $\mathrm{m} / \mathrm{z}$ value if they are not well separated. It should be noted that the differentiation of isobaric APEO ion species was enabled by introducing the gas-phase ion mobility separation. As an example, the singly charged $\mathrm{NP}_{5} \mathrm{EO}$ sodiated ion peak and the doubly charged sodium adduct ion peak from nonylphenol pentadecaethoxylate $\left(\mathrm{NP}_{15} \mathrm{EO}\right)$ ethoxymer shared the same nominal $m / z$ value of 463 . The quantitative determination of $\mathrm{NP}_{5}$ EO ethoxymer might be overestimated if it cannot be separated as a single peak. This situation would not be alleviated by the choice of an alternate adduct ion, such as hydrogen or ammonium, since the use of these ions produced similar interferences, with the mass scale shifted correspondingly. As shown in Fig. 2a, IM-MS parted the singly charged $\mathrm{NP}_{5}$ EO ethoxymer and doubly charged $\mathrm{NP}_{15} \mathrm{EO}$ ethoxymer into two baseline resolved peaks with drift times differing by $0.91 \mathrm{~ms}$. A similar result was given for the separation of singly 
charged nonylphenol hexaethoxylate $\left(\mathrm{NP}_{6} \mathrm{EO}\right)$ peak and doubly charged nonylphenol heptadecaethoxylate $\left(\mathrm{NP}_{17} \mathrm{EO}\right)$ counterpart, as indicated in Fig. 2b. This demonstrated the power of ion mobility to achieve a good separation for isobaric APEO ethoxymers, and thus to quantify the components precisely in a much shorter time. The high-efficiency and time-saving ion mobility approach capable of charge state separation for APEOs offered a promising alternative to traditional chromatographic protocol for removing the effects of isobaric interference. Because of the inherent speed of analysis, the solvent-free and cost-effective IM-MS methodology has important potential to allow a great quantity of samples to be acquired in a high-throughput fashion, indicating applicability to areas in which improved productivity becomes critical.

\subsection{Comprehensive two-dimensional separation of APEOs by HILIC $\times I M-M S$}

In this study, we have engaged in developing an effective HILIC $\times$ IM-MS tool by incorporating the resolving capabilities of both HILIC and IM-MS for the analysis of APEOs. When HILIC was hyphenated in tandem with IM-MS, an Atlantis HILIC Silica chromatographic column with the dimension of $150 \mathrm{~mm} \times 2.1 \mathrm{~mm}$ was utilized instead of $250 \mathrm{~mm} \times 4.6 \mathrm{~mm}$ to enhance mass spectrometric signal intensity (see Section 2.2). Certain chromatographic parameters, such as gradient elution profile and flow rate of the mobile phase, were finely re-adjusted based on the experimental results of previous liquid chromatographic testing. With the ESI interface and the aprotic solvent acetonitrile, APEOs showed a great affinity for the ubiquitous cations, e.g., $\mathrm{Na}^{+}, \mathrm{NH}_{4}{ }^{+}, \mathrm{H}^{+}$, which might be present in the solvents, the ionization chamber and solvent transfer lines used. Under these circumstances, the relative abundance of the adduct ions is variable and difficult to reproduce because of the uncertainness of distribution of ion adducts. To address this problem, it is recommended that a sodium acetate buffer be added into the mobile phase to provide sufficient sodium ions for the entire ethoxylate series [50]. Maintaining the effects of pre-ionization separation on APEOs afforded by the first-dimensional HILIC, the whole chromatographic eluting APEO species underwent further second-dimensional post-ionization ion mobility separation in an on-line manner without diminishing the fidelity of the first dimension of separation. The retention time, drift time and resolution for OPEOs and NPEOs are shown in Tables 1 and 2.

The nested data set derived from the HILIC $\times$ IM-MS separation are demonstrated by three correlated visualized color-coded plots (white representing the most abundant signal whilst black least abundant), i.e., drift time versus retention time plot (data summed over all $\mathrm{m} / \mathrm{z}$ values), $\mathrm{m} / \mathrm{z}$ versus retention time plot (data summed over all drift times) and $m / z$ versus drift time plot (data summed over all retention times). As displayed in the drift time versus retention time plot for OPEOs (Fig. 3), HILIC realized the first-dimensional separation for OPEO ethoxymers along the axis of retention time based on the difference in hydrophobicity, and IM-MS then achieved the second-dimensional separation along the axis of drift time based on the difference in ion mobility. As labeled in the plot, two distinguishable families of serial spots, individually corresponding to high-intensity singly charged and low-intensity doubly charged OPEOs, were aligned along the two regions. The mobility increases with increasing electric charges for OPEO ethoxy oligomers. Ions having higher charge will experience greater separation field strengths and pass through the ion mobility region during a shorter period than those with single charge. For each charge-state family, the ethoxy homologous behavior is substantiated by essentially the same increment in the observed drift time distribution, shown to vary linearly with the degree of ethoxylation. Larger and more ethoxylated oligomers with extended structures

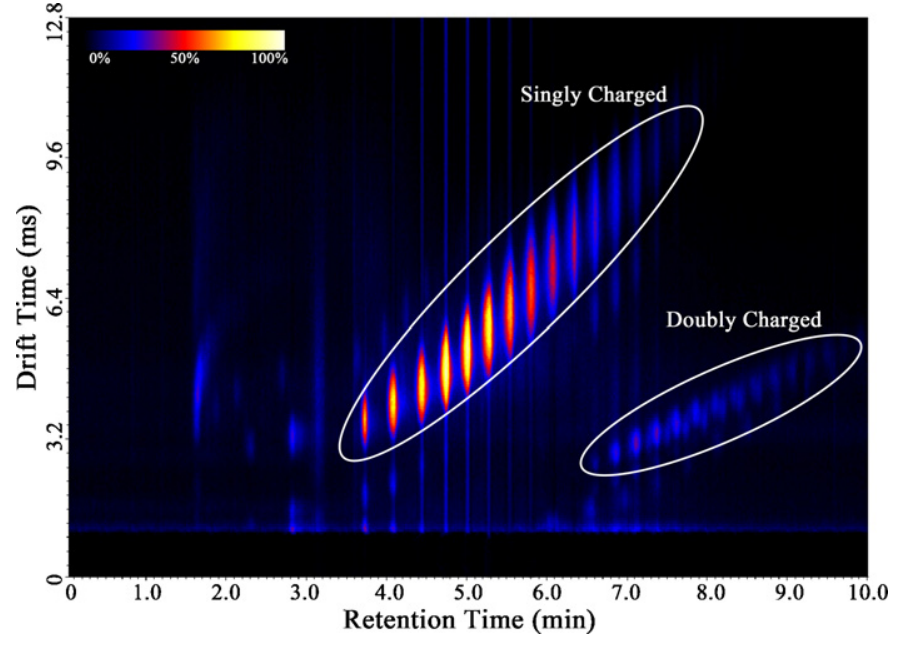

Fig. 3. The drift time versus retention time plot of OPEOs.

will experience a greater number of collisions with the background inert gas and thus drifts more slowly, while low molecular weight and less ethoxylated components with compact structures comprise a smaller cross-section and migrates more rapidly across the ion mobility device. Examination of the experimental data indicates that, in order to incorporate an additional electric charge, OPEO oligomer must be at least a minimum length of 15 ethylene oxide units. Presumably, the oligomer should be large enough to stabilize the increase in repulsive Coulomb interactions that arise from inclusion of an additional charge.

The $m / z$ versus retention time plot (Fig. 4) summarized the acquired data, showing two well-defined clusters of signals linearly scattered in regular equidistance. One cluster distributed along the diagonal line from the middle to top right of the plot, representing singly charged OPEO ion species. Some insights into the pattern of alignment revealed that each spot corresponded to an oligomer with a different number of repeated ethoxy units. The spacing between two adjacent spots was shown to be an equal $\mathrm{m} / \mathrm{z}$ difference of 44 , which was the mass of one ethylene oxide unit. The individual spot may be classified into vertically adjacent subsections, indicating the formation of various types of adduct ions, e.g., $[\mathrm{M}+\mathrm{Na}]^{+},\left[\mathrm{M}+\mathrm{NH}_{4}\right]^{+},[\mathrm{M}+\mathrm{H}]^{+}$, etc. The other cluster emerged in the lower right-hand part of the plot. The evenly spaced difference of 22 in $m / z$ of the associated spots in the region allowed us to

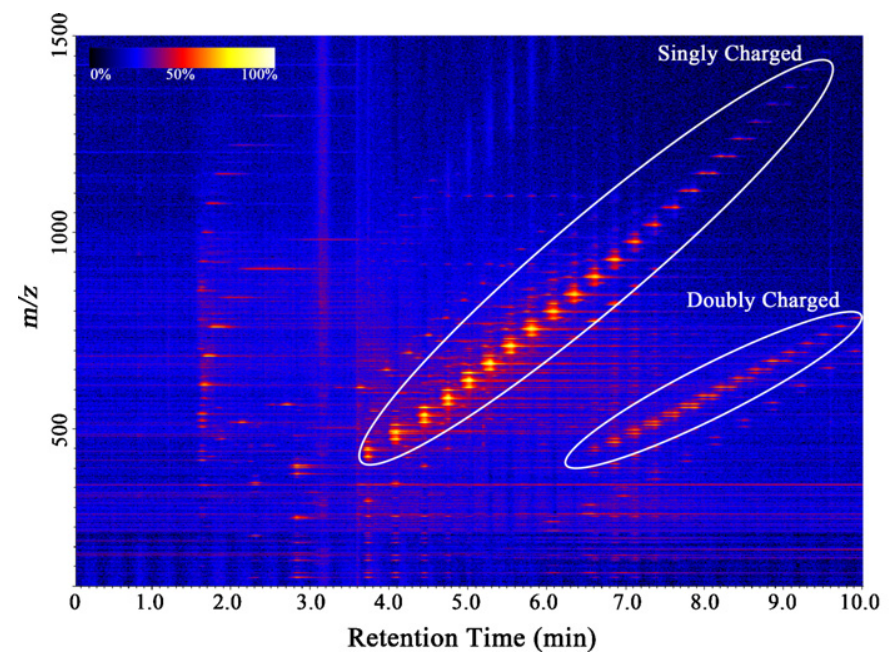

Fig. 4. The $m / z$ versus retention time plot of OPEOs. 
Table 1

Formula, logarithmic value of octanol/water partition coefficient $\left(\log K_{o w}\right)$, retention time, drift time and resolution of OPEO ethoxymers.

\begin{tabular}{|c|c|c|c|c|c|c|}
\hline OPEO ethoxymers & Formula & $\log K_{o w}$ & $\begin{array}{l}\text { Retention time } \\
\text { (min) }\end{array}$ & $\begin{array}{l}\text { Resolution by } \\
\text { HILIC }\end{array}$ & Drift time (ms) & $\begin{array}{l}\text { Resolution by } \\
\text { IM-MS }\end{array}$ \\
\hline $\mathrm{OP}_{5} \mathrm{EO}$ & $\mathrm{C}_{24} \mathrm{H}_{42} \mathrm{O}_{6}$ & 3.99 & 3.74 & - & 3.65 & - \\
\hline $\mathrm{OP}_{6} \mathrm{EO}$ & $\mathrm{C}_{26} \mathrm{H}_{46} \mathrm{O}_{7}$ & 3.71 & 4.10 & 2.47 & 4.03 & 0.19 \\
\hline $\mathrm{OP}_{7} \mathrm{EO}$ & $\mathrm{C}_{28} \mathrm{H}_{50} \mathrm{O}_{8}$ & 3.44 & 4.45 & 2.02 & 4.35 & 0.14 \\
\hline $\mathrm{OP}_{8} \mathrm{EO}$ & $\mathrm{C}_{30} \mathrm{H}_{54} \mathrm{O}_{9}$ & 3.16 & 4.74 & 1.63 & 4.74 & 0.15 \\
\hline $\mathrm{OP}_{9} \mathrm{EO}$ & $\mathrm{C}_{32} \mathrm{H}_{58} \mathrm{O}_{10}$ & 2.89 & 5.01 & 1.54 & 5.18 & 0.17 \\
\hline $\mathrm{OP}_{10} \mathrm{EO}$ & $\mathrm{C}_{34} \mathrm{H}_{62} \mathrm{O}_{11}$ & 2.62 & 5.29 & 1.49 & 5.63 & 0.16 \\
\hline $\mathrm{OP}_{11} \mathrm{EO}$ & $\mathrm{C}_{36} \mathrm{H}_{66} \mathrm{O}_{12}$ & 2.34 & 5.54 & 1.29 & 6.08 & 0.15 \\
\hline $\mathrm{OP}_{12} \mathrm{EO}$ & $\mathrm{C}_{38} \mathrm{H}_{70} \mathrm{O}_{13}$ & 2.07 & 5.81 & 1.40 & 6.59 & 0.16 \\
\hline $\mathrm{OP}_{13} \mathrm{EO}$ & $\mathrm{C}_{40} \mathrm{H}_{74} \mathrm{O}_{14}$ & 1.79 & 6.07 & 1.25 & 7.10 & 0.15 \\
\hline $\mathrm{OP}_{14} \mathrm{EO}$ & $\mathrm{C}_{42} \mathrm{H}_{78} \mathrm{O}_{15}$ & 1.52 & 6.34 & 1.36 & 7.68 & 0.16 \\
\hline $\mathrm{OP}_{15} \mathrm{EO}$ & $\mathrm{C}_{44} \mathrm{H}_{82} \mathrm{O}_{16}$ & 1.24 & 6.60 & 1.48 & 8.13 & 0.13 \\
\hline $\mathrm{OP}_{16} \mathrm{EO}$ & $\mathrm{C}_{46} \mathrm{H}_{86} \mathrm{O}_{17}$ & 0.97 & 6.87 & 1.52 & 8.70 & 0.17 \\
\hline $\mathrm{OP}_{17} \mathrm{EO}$ & $\mathrm{C}_{48} \mathrm{H}_{90} \mathrm{O}_{18}$ & 0.69 & 7.12 & 2.02 & 9.22 & 0.17 \\
\hline $\mathrm{OP}_{18} \mathrm{EO}$ & $\mathrm{C}_{50} \mathrm{H}_{94} \mathrm{O}_{19}$ & 0.42 & 7.38 & 3.09 & 9.73 & 0.18 \\
\hline $\mathrm{OP}_{19} \mathrm{EO}$ & $\mathrm{C}_{52} \mathrm{H}_{98} \mathrm{O}_{20}$ & 0.15 & 7.62 & 2.41 & 10.37 & 0.26 \\
\hline $\mathrm{OP}_{20} \mathrm{EO}$ & $\mathrm{C}_{54} \mathrm{H}_{102} \mathrm{O}_{21}$ & -0.13 & 7.85 & 2.96 & 10.82 & 0.22 \\
\hline
\end{tabular}

Table 2

Formula, logarithmic value of octanol/water partition coefficient $\left(\log K_{o w}\right)$, retention time, drift time and resolution of NPEO ethoxymers.

\begin{tabular}{|c|c|c|c|c|c|c|}
\hline NPEO ethoxymers & Formula & $\log K_{o w}$ & $\begin{array}{l}\text { Retention time } \\
(\mathrm{min})\end{array}$ & $\begin{array}{l}\text { Resolution by } \\
\text { HILIC }\end{array}$ & Drift time (ms) & $\begin{array}{l}\text { Resolution by } \\
\text { IM-MS }\end{array}$ \\
\hline $\mathrm{NP}_{5} \mathrm{EO}$ & $\mathrm{C}_{25} \mathrm{H}_{44} \mathrm{O}_{6}$ & 4.48 & 3.68 & - & 3.90 & - \\
\hline $\mathrm{NP}_{6} \mathrm{EO}$ & $\mathrm{C}_{27} \mathrm{H}_{48} \mathrm{O}_{7}$ & 4.20 & 4.00 & 2.82 & 4.36 & 0.30 \\
\hline $\mathrm{NP}_{7} \mathrm{EO}$ & $\mathrm{C}_{29} \mathrm{H}_{52} \mathrm{O}_{8}$ & 3.93 & 4.32 & 2.09 & 4.75 & 0.24 \\
\hline $\mathrm{NP}_{8} \mathrm{EO}$ & $\mathrm{C}_{31} \mathrm{H}_{56} \mathrm{O}_{9}$ & 3.66 & 4.64 & 2.15 & 5.20 & 0.25 \\
\hline $\mathrm{NP}_{9} \mathrm{EO}$ & $\mathrm{C}_{33} \mathrm{H}_{60} \mathrm{O}_{10}$ & 3.38 & 4.87 & 1.36 & 5.59 & 0.19 \\
\hline $\mathrm{NP}_{10} \mathrm{EO}$ & $\mathrm{C}_{35} \mathrm{H}_{64} \mathrm{O}_{11}$ & 3.11 & 5.13 & 1.23 & 6.05 & 0.20 \\
\hline $\mathrm{NP}_{11} \mathrm{EO}$ & $\mathrm{C}_{37} \mathrm{H}_{68} \mathrm{O}_{12}$ & 2.83 & 5.38 & 1.05 & 6.70 & 0.25 \\
\hline $\mathrm{NP}_{12} \mathrm{EO}$ & $\mathrm{C}_{39} \mathrm{H}_{72} \mathrm{O}_{13}$ & 2.56 & 5.63 & 1.01 & 7.28 & 0.21 \\
\hline $\mathrm{NP}_{13} \mathrm{EO}$ & $\mathrm{C}_{41} \mathrm{H}_{76} \mathrm{O}_{14}$ & 2.28 & 5.89 & 1.14 & 7.87 & 0.20 \\
\hline $\mathrm{NP}_{14} \mathrm{EO}$ & $\mathrm{C}_{43} \mathrm{H}_{80} \mathrm{O}_{15}$ & 2.01 & 6.17 & 1.47 & 8.26 & 0.17 \\
\hline $\mathrm{NP}_{15} \mathrm{EO}$ & $\mathrm{C}_{45} \mathrm{H}_{84} \mathrm{O}_{16}$ & 1.73 & 6.41 & 1.22 & 8.78 & 0.19 \\
\hline $\mathrm{NP}_{16} \mathrm{EO}$ & $\mathrm{C}_{47} \mathrm{H}_{88} \mathrm{O}_{17}$ & 1.46 & 6.68 & 1.00 & 9.36 & 0.22 \\
\hline $\mathrm{NP}_{17} \mathrm{EO}$ & $\mathrm{C}_{49} \mathrm{H}_{92} \mathrm{O}_{18}$ & 1.19 & 6.93 & 0.90 & 9.88 & 0.21 \\
\hline $\mathrm{NP}_{18} \mathrm{EO}$ & $\mathrm{C}_{51} \mathrm{H}_{96} \mathrm{O}_{19}$ & 0.91 & 7.18 & 1.13 & 10.34 & 0.19 \\
\hline $\mathrm{NP}_{19} \mathrm{EO}$ & $\mathrm{C}_{53} \mathrm{H}_{100} \mathrm{O}_{20}$ & 0.64 & 7.43 & 1.21 & 10.86 & 0.26 \\
\hline $\mathrm{NP}_{20} \mathrm{EO}$ & $\mathrm{C}_{55} \mathrm{H}_{104} \mathrm{O}_{21}$ & 0.36 & 7.68 & 1.29 & 11.38 & 0.35 \\
\hline
\end{tabular}

immediately identify this set of peaks as the doubly charged ion species. The exact spots representing $[\mathrm{M}+2 \mathrm{Na}]^{2+},\left[\mathrm{M}+2 \mathrm{NH}_{4}\right]^{2+}$, $[\mathrm{M}+2 \mathrm{H}]^{2+}$, etc., were found in the plot. The linear slope of the oblique line constructed by +1 charge state OPEO points was approximately twice as much as that of +2 charge state species. The information-rich $m / z$ versus retention time plot also confirmed that OPEOs were eluted in the order of increasing size of ethoxylate oligomers by HILIC of the first dimension. The data presented in the $\mathrm{m} / \mathrm{z}$ versus drift time plot (Fig. 5) demonstrated that two beams of ions were projected along different trajectories, broadly falling into two families with high-intensity singly charged species on the right and low-intensity doubly charged species on the left (partitioned by a diagonal line). Charge state, therefore, played a vital role in overall drifting mobilities for OPEO ethoxymers. For a given $\mathrm{m} / \mathrm{z}$ value, ions bearing two charges traversed more rapidly than singly charged equivalents. Therefore, IM-MS was found to be a good choice to provide cleanly separated ions of different charge states, thus reduce complexity associated with multiple charging phenomenon occurred during electrospray and aid in the simplification of mass congestion and enhancement of spectral interpretation.

The established HILIC $\times$ IM-MS protocol was evaluated for limit of detection (LOD), linear dynamic range and precision. LODs, based on injection of a $10 \mu \mathrm{L}$ aliquot, calculated as a signal-to-noise $(\mathrm{S} / \mathrm{N})$ ratio of 3, were from 0.05 to $2.0 \mathrm{ng}$ for OPEO oligomers and from 0.1 to $3.0 \mathrm{ng}$ for NPEO oligomers. The linear dynamic range of the HILIC $\times$ IM-MS instrumentation was evaluated by analyzing six serial standard solutions. Calibration curves for individual APEO oligomer were generated using linear regression analyses and gave good fits, with the correlation coefficients between 0.9924 and 0.9975 for OPEOs and between 0.9919 and 0.9962 for NPEOs. The within- and between-day precisions for APEOs were all less than the relative standard deviations (RSDs) of $12 \%$ and $15 \%$, respectively. These preliminary experimental results provide sufficient stimulus for the full investigation of the analytical pipeline, which will be the subject of our further dedicated study.

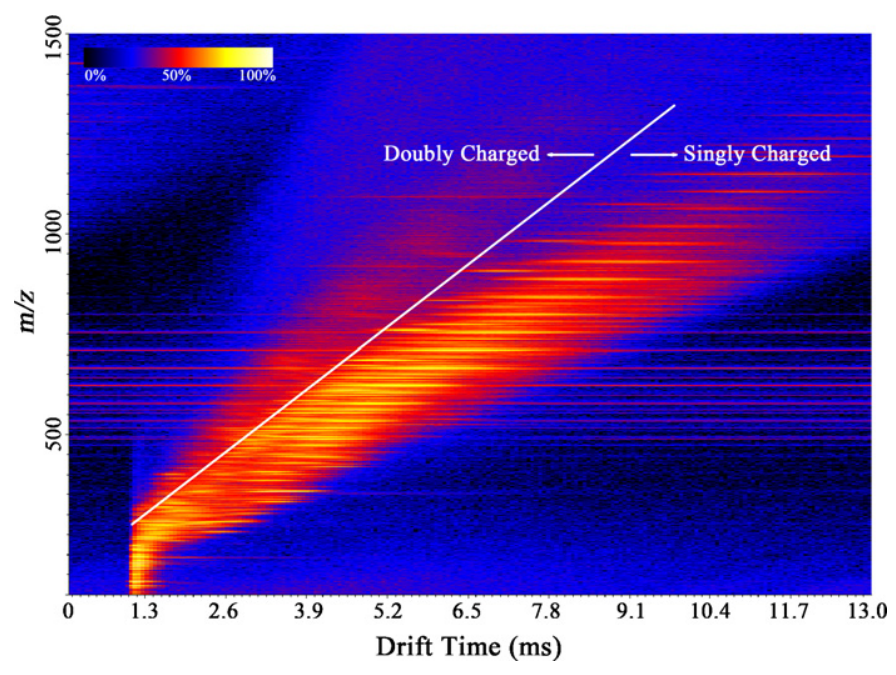

Fig. 5. The $m / z$ versus drift time plot of OPEOs. 


\subsection{Evaluation on orthogonality and practical peak capacity of the HILIC $\times I M-M S$ system}

Orthogonality and peak capacity are interrelated parameters for estimating difference in selectivity or resolving power of a comprehensive two-dimensional system. Normally, orthogonality is dependent not only on the separation mechanism but also on the properties of the solutes and the separation conditions. Based on the approach established by Liu and coworkers [51], factor analysis was utilized to quantitatively estimate the degree of HILIC $\times$ IM-MS separation orthogonality. Correlation coefficient $(r)$ is a frequently used parameter to evaluate the orthogonality between the two dimensions. A perfect retention correlation is obtained when $r=1$, and truly orthogonal separation is achieved when $r=0$. Most two-dimensional separations lie between perfect correlation and perfect orthogonality. In our study, the $r$-value was calculated based on a correlation matrix incorporating the retention time and drift time of APEOs in the two dimensions. The peak spreading angle $(\beta)$ between the retention axes in the orthogonal retention space was computed as the arc cosine value of $r$. A value of $\beta$ close to $90^{\circ}$ indicates a nearly orthogonal separation. The calculated correlation coefficient and peak spreading angle were 0.2191 and $77.34^{\circ}$ for OPEO ethoxy oligomers, and 0.1499 and $81.43^{\circ}$ for NPEO ethoxy oligomers. The HILIC $\times$ IM-MS separation is close to perfect orthogonality under the experimental conditions (see Supplementary Material, Fig. S2 and S3).

The measured peak capacities for HILIC separation of the first dimension and ion mobility separation of the second dimension are 134 and 8, respectively, computed from the ratio of total retention time to mean peak width at half height in each dimension. Hence, the theoretical peak capacity for the HILIC $\times$ IM-MS plane is 1072 . Based on the average peak spreading angle of $79.39^{\circ}$, the experimentally derived peak capacity is calculated to be approximately 972. The actual peak capacity obtained from the comprehensive two-dimensional separation is, respectively, 7 and 122 times higher than those from the two dimensions used alone. Results demonstrate that ion mobility separation prior to mass analysis increases peak capacity through added dimensionality in measurement, thus showing great improvement from the perspective of profiling. By combining the high-efficiency ion mobility separation with HILIC, a dramatically increased analytical peak capacity as well as greater richness of information is achieved on a very rapid millisecond timescale such that there is no increase in the time associated with HILIC $\times$ IM-MS data acquisition compared with HILIC-MS alone.

\section{Conclusions}

In this work, the advantages of integrating HILIC with the high analytical speed and separation capability provided by IM-MS has inspired the development of a comprehensive twodimensional system for the separation and analysis of APEOs. The first-dimensional HILIC, as a pre-ionization separation technique, realizes satisfactory chromatographic resolution for APEO ethoxylate oligomers on account of their ethoxy chain length prior to electrospray ionization. On the other hand, IM-MS introduces an additional dimension of ion mobility-based post-ionization separation and offers a rapid and powerful means of separation for APEO ethoxymers based on their size, shape and electric charge. The high-throughput ion mobility approach demonstrates a promising alternative to traditional chromatographic protocol for removing the effects of isobaric interference. Harnessing the combination of HILIC and IM-MS, comprehensive resolution according to both hydrophobicity difference and mobility disparity has been achieved for APEO ethoxy homologues, with each dimension selective to particular compound characteristics. A fast-scanning TOF-MS enables plenty of information to be collected during the entire procedure. The developed HILIC $\times$ IM-MS plane exhibits unique selectivity and increased peak capacity for the measurement of APEOs.

\section{Acknowledgements}

The authors thank Dr. Peter J. Lee and Dr. Wei-Bin Chen at Waters Corporation for their discussion on data interpretation. This work was financially supported by the National Natural Science Foundation of China (20890112, 20825519, 20921063, 51102220), the National Basic Research Program of China (2011CB936001), the Quality Inspection Public Welfare Scientific Research Foundation of China (201010013, 201010019), and the Science Research Program of Chinese Academy of Inspection and Quarantine (2012JK021).

\section{Appendix A. Supplementary data}

Supplementary data associated with this article can be found, in the online version, at doi:10.1016/j.jjms.2012.02.010.

\section{References}

[1] T.V. Morles, M.E.T. Padrón, Z.S. Ferrera, J.J.S. Rodríguez, Trends Anal. Chem. 28 (2009) 1186-1200.

[2] T.Y. Chiu, N. Paterakis, M.D. Scrimshaw, E. Cartmell, J.N. Lester, Crit. Rev. Environ. Sci. Technol. 40 (2010) 199-238.

[3] M. Ahel, W. Giger, M. Koch, Water Res. 28 (1994) 1131-1142.

[4] M.R. Servos, R.J. Maguire, D.T. Bennie, H.-B. Lee, P.M. Cureton, N. Davidson, R. Sutcliffe, D.F.K. Rawn, Hum. Ecol. Risk Assess. 9 (2003) 569-587.

[5] D.T. Bennie, Water Qual. Res. J. Can. 34 (1999) 79-122.

[6] G.G. Ying, B. Williams, R. Kookana, Environ. Int. 28 (2002) 215-226.

[7] A. Soares, B. Guieysse, B. Jefferson, E. Cartmell, J.N. Lester, Environ. Int. 34 (2008) 1033-1049.

[8] W. Giger, P.H. Brunner, C. Schaffner, Science 225 (1984) 623-625.

[9] K.H. Langford, M.D. Scrimshaw, J.W. Birkett, J.N. Lester, Water Res. 39 (2005) 870-876.

[10] J. Lu, Q. Jin, Y.L. He, J. Wu, W.Y. Zhang, J. Zhao, Chemosphere 71 (2008) 345-351

[11] R. White, S. Jobling, S.A. Hoare, J.P. Sumpter, M.G. Parker, Endocrinology 135 (1994) 175-182.

[12] M.R. Servos, Water Qual. Res. J. Can. 34 (1999) 123-177.

[13] S.C. Laws, S.A. Carey, J.M. Ferrell, G.J. Bodman, R.L. Cooper, Toxicol. Sci. 54 (2000) $154-167$.

[14] Ė.B. Dussault, J.P. Sherry, H.-B. Lee, B.K. Burnison, D.T. Bennie, M.R. Servos, Hum. Ecol. Risk Assess. 11 (2005) 353-364.

[15] Directive 2003/53/EC of the European Parliament and of the Council of 18 June 2003 Amending for the 26th Time the Council Directive 76/769/EEC Relating to Restrictions on the Marketing and Use of Certain Dangerous Substances and Preparations (Nonylphenol, Nonylphenol Ethoxylate and Cement).

[16] Commission Decision of 9 July 2009 Establishing the Ecological Criteria for the Award of the Community Ecolabel for Textile Products (2009/567/EC).

[17] Öko-Tex Standard 1000, Öko-Tex International, Ausgabe/Edition 01/2011.

[18] OSPAR List of Chemicals for Priority Action. http://www.ospar.org.

[19] Decision No 2455/2001/EC of the European Parliament and of the Council of 20 November 2001 Establishing the List of Priority Substances in the Field of Water Policy and Amending Directive 2000/60/EC.

[20] P. Sandra, F. David, J. High Res. Chromatogr. 13 (1990) 414-417.

[21] C. Wahlberg, L. Renberg, U. Wideqvist, Chemosphere 20 (1990) 179-195.

[22] G. Gatidou, N.S. Thomaidis, A.S. Stasinakis, T.D. Lekkas, J. Chromatogr. A 1138 (2007) 32-41.

[23] E. Stephanou, Chemosphere 13 (1984) 43-51.

[24] C. Wang, Q. Ma, X. Wang, J. AOAC Int. 90 (2007) 1411-1417.

[25] M. Ahel, W. Giger, Anal. Chem. 57 (1985) 2584-2590.

[26] M. Fountoulakis, P. Drillia, C. Pakou, A. Kampioti, K. Stamatelatou, G. Lyberatos, J. Chromatogr. A 1089 (2005) 45-51.

[27] L. Núñez, E. Turiel, J.L. Tadeo, J. Chromatogr. A 1146 (2007) 157-163.

[28] F.O. Ayorinde, P. Hambright, T.N. Porter, Q.L. Keith Jr., Rapid Commun. Mass Spectrom. 13 (1999) 2474-2479.

[29] P.L. Ferguson, C.R. Iden, B.J. Brownawell, Anal. Chem. 72 (2000) 4322-4330.

[30] R. Loos, G. Hanke, G. Umlauf, S.J. Eisenreich, Chemosphere 66 (2007) 690-699.

[31] F. Houde, C. DeBlois, D. Berryman, J. Chromatogr. A 961 (2002) 245-256.

[32] M. Cantero, S. Rubio, D. Pérez-Bendito, J. Chromatogr. A 1067 (2005) 161-170.

[33] S. González, M. Petrović, M. Radetic, P. Jovancic, V. Ilic, D. Barceló, Rapid Commun. Mass Spectrom. 22 (2008) 1445-1454.

[34] M.M. Bushey, J.W. Jorgenson, Anal. Chem. 62 (1990) 161-167.

[35] Z. Liu, J.B. Phillips, J. Chromatogr. Sci. 29 (1991) 227-231.

[36] Y. Hirata, T. Hashiguchi, E. Kawata, J. Sep. Sci. 26 (2003) 531-535

[37] D.A. Michels, S. Hu, K.A. Dambrowtz, M.J. Eggertson, K. Lauterbach, N.J. Dovichi, Electrophoresis 25 (2004) 3098-3105. 
[38] Q. Ma, C. Wang, H. Bai, H.W. Xi, G.C. Xi, X.M. Ren, Y. Yang, L.H. Guo, J. Am. Soc. Mass Spectrom. 22 (2011) 1851-1861.

[39] E.L. Harry, D.J. Weston, A.W. Bristow, I.D. Wilson, C.S. Creaser, J. Chromatogr. B 871 (2008) 357-361.

[40] X.Y. Liu, S.J. Valentine, M.D. Plasencia, S. Trimpin, S. Naylor, D.E. Clemmer, J. Am. Soc. Mass Spectrom. 18 (2007) 1249-1264.

[41] Y.J. Lee, C.S. Hoaglund-Hyzera, C.A.S. Barnes, A.E. Hilderbrand, S.J. Valentine, D.E. Clemmer, J. Chromatogr. B 782 (2002) 343-351.

[42] C. Eckers, A.M. Laures, K. Giles, H. Major, S. Pringle, Rapid Commun. Mass Spectrom. 21 (2007) 1255-1263.

[43] G.A. Eiceman, Z. Karpas, Ion Mobility Spectrometry, second ed., CRC Press, Boca Raton, 2005.
[44] M. Petrovic, A. Diaz, F. Ventura, D. Barceló, Anal. Chem. 73 (2001) 5886-5895.

[45] M. Petrovic, D. Barceló, J. Mass Spectrom. 36 (2001) 1173-1185.

[46] V. Andreu, E. Ferrer, J.L. Rubio, G. Font, Y. Picó, Sci. Total Environ. 378 (2007) $124-129$.

[47] T. Reemtsma, J. Chromatogr. A 1000 (2003) 477-501.

[48] P.L. Ferguson, C.R. Iden, B.J. Brownawell, J. Chromatogr. A 938 (2001) 79-91.

[49] M. Takino, S. Daishima, K. Yamaguchi, J. Chromatogr. A 904 (2000) 65-72.

[50] D.Y. Shang, M.G. Ikonomou, R.W. Macdonald, J. Chromatogr. A 849 (1999) $467-482$

[51] Z. Liu, D.G. Patterson, Anal. Chem. 67 (1995) 3840-3845. 